\title{
Biosorption valorization of floating and submerged macrophytes for heavy-metal removal in a multi-component system
}

\author{
Akhilesh Bind $^{1} \cdot$ Anamika Kushwaha $^{2,3} \cdot$ Gitika Devi $^{4} \cdot$ Shivani Goswami $^{5} \cdot$ Bahnika Sen $^{4} \cdot$ Veeru Prakash ${ }^{1}$
}

Received: 18 January 2019 / Accepted: 5 May 2019 / Published online: 14 May 2019

(c) The Author(s) 2019

\begin{abstract}
This study comprises the comparative evaluation of floating (Azolla filiculoides) and submerged (Hydrilla verticillata) macrophytes for potential biosorption of $\mathrm{Cu}(\mathrm{II}), \mathrm{Cr}(\mathrm{VI}), \mathrm{As}(\mathrm{III})$ and $\mathrm{Pb}(\mathrm{II})$ from aqueous solution in a multi-component study. Statistically valid Plackett-Burman design of experiments was employed with four heavy metals at two different levels by varying their initial concentration in the range $10-50 \mathrm{mg} \mathrm{L}^{-1}$ for both the macrophytes. The maximum removal efficiency for $\mathrm{Pb}$ (II) was obtained for both the biosorbents, i.e., Azolla sp. (81.4\%) and Hydrilla sp. (84.3\%) within $4 \mathrm{~h}$ of the experimental runs, with an initial concentration of $10 \mathrm{mg} \mathrm{L}^{-1}$ of all the heavy metals. Followed by $\mathrm{Pb}$ (II) removal, a declining trend for the removal (\%) for $\mathrm{Cu}(\mathrm{II}), \mathrm{As}(\mathrm{III})$ and $\mathrm{Cr}(\mathrm{VI})$ was obtained, for all the experimental runs. Also, the minimum removal (\%) for all the experimental runs was attained at $25 \mathrm{mg} \mathrm{L}^{-1}$ (maximum) for all the heavy-metal concentration level. The removal efficiency (\%) trends follow the order: $\mathrm{Pb}(\mathrm{II})>\mathrm{Cu}(\mathrm{II})>\mathrm{As}(\mathrm{III})>\mathrm{Cr}(\mathrm{VI})$ for both the biosorbents. Analysis of variance and Student's t test of the metal bioremoval revealed that main (individual) effect due to the metals was highly significant $(P$ value $<0.05)$ on each other's removal. Student's test results revealed that both $\mathrm{Pb}$ (II) and $\mathrm{Cu}$ (II) strongly inhibited both $\mathrm{Cu}$ (II) removal $(P$ value $<0.01)$, while $\mathrm{Cr}(\mathrm{VI})$ has only inhibitory effect on $\mathrm{Pb}$ (II) removal. Henceforth, all these results simultaneously depicted good potential of the aquatic macrophytes for the biosorption capability of heavy metal and the effect of individual metals on each other's removal in the multi-component system.
\end{abstract}

Keywords Heavy metals · Multi-component system · Aquatic macrophytes · Plackett-Burman design of experiments · Azolla filiculoides $\cdot$ Hydrilla verticillata

Akhilesh Bind and Anamika Kushwaha contributed equally to this work.

Akhilesh Bind

akhileshbind@gmail.com

1 Department of Biochemistry and Biochemical Engineering, Sam Higginbottom University of Agriculture, Technology and Sciences, Prayagraj, Uttar Pradesh 211007, India

2 Department of Biotechnology, Motilal Nehru National Institute of Technology Allahabad, Prayagraj, Uttar Pradesh 211004, India

3 Department of Chemistry, Indian Institute of Technology Kanpur, Kanpur, Uttar Pradesh 208016, India

4 Department of Environmental Science, Gauhati University, Guwahati, Assam 781014, India

5 Department of Biotechnology, Brahmanand College, Chhatrapati Shahu Ji Maharaj University, Kanpur, Uttar Pradesh 208001, India

\section{Introduction}

Globally, heavy metals are very well recognized for their ill effects since ages, representing a serious environmental concern and threat to the ecosystem (Ahmad et al. 2018; Kushwaha et al. 2018). Unlike organic contaminants, heavy metals (HMs), viz., copper, chromium, arsenic and lead, are among the prime pollutants of the aquatic bodies because of their toxic, persistent, non-degradable nature, and bioaccumulative capability among the food web and tissues in human bodies (Singh et al. 2019; Bind et al. 2018; Goswami et al. 2017a; Arul Manikandan et al. 2016). It causes serious problems to human beings in relation to the respiratory, reproductive, cardiovascular, endocrine and immunological systems leading to insomnia, irritability, anemia, dizziness and muscles weakness (Kushwaha et al. 2015, 2017a, Goswami et al. 2019). 
With the stringent environmental legislations along with the techno-economical inadequacy of the conventional technology, utilization for the potential removal of heavy metals have lead to the exploration of better, efficient and economical biosorbent (Ibrahim et al. 2016; Kushwaha et al. 2017b; Goswami et al. 2018a, b). In addition, the sequestration of heavy metals follows a rapid as well as reversible reaction of $\mathrm{HM}$ ions with the functional groups present in the polymeric cell wall of biosorbents (Volesky 1990). Numerous studies have been reported for HM removal by utilizing biosorbents, viz., agricultural wastes, seaweeds, living or dead microorganisms, and wastes from industries (Bind et al. 2018; Ahn and Hong 2015).

In addition, HMs contaminant mostly occurs with other organic and/or inorganic pollutants in wastewater. It is important to consider a biosorbent which is capable of the removal of these pollutants in single as well as in the mixture component system. This could lead to a synergistic or antagonistic effect on the removal of HMs in the multicomponent system depending on their interactions with each other as well as with the biosorbent. Therefore, examination of the interactions and removal efficiency of HMs in a multi-component system is of utmost importance. Also, there is not ample literature reporting the interactions of HMs with each other as well as with the biosorbent in a multi-component system.

In accordance with the aforementioned aspects, the present study investigated the HM removal from the simulated aqueous HM solutions in a multi-component system with their interactions with each other. In the literature, various aquatic macrophytes have already been reported for their potential of HM removal and have already proved their potential for the wastewater treatment (Showqi et al. 2018). Here, two different types of aquatic macrophytes, i.e., Azolla filiculoides (floating macrophytes) and Hydrilla verticillata (submerged macrophytes) have been chosen for the performance evaluation of the two biosorbents (Bind et al. 2018). A Plackett-Burman design was deployed with four different HMs (copper, $\mathrm{Cu}(\mathrm{II})$; chromium, $\mathrm{Cr}(\mathrm{VI})$; arsenic, $\mathrm{As}(\mathrm{III})$ and lead, $\mathrm{Pb}(\mathrm{II})$ ) at two different levels by varying their initial concentration in the range $10-25 \mathrm{mg} \mathrm{L}^{-1}$ for both the macrophytes (biosorbents). The interpretation of the removal efficiencies was further analyzed through Student's ' $t$ ' test and variance analysis (ANOVA) for an insight into the significance and effect of the chosen HMs on each other's removal in a multi-component system. Further, investigations were performed employing field emission scanning electron microscopy (FESEM) equipped with energy-dispersive spectroscopy (EDX) and Fourier-transform infrared spectroscopy (FTIR).

\section{Materials and methods}

\section{Biosorbent source and metal solution preparation}

Two different biosorbents were collected from the nearby locality as mentioned in our previous individual metal biosorption study along with their preparation and characterization (Bind et al. 2018). All the individual HM stock solutions of $\mathrm{Pb}(\mathrm{II}), \mathrm{As}(\mathrm{III}), \mathrm{Cu}(\mathrm{II})$ and $\mathrm{Cr}(\mathrm{VI})$ were prepared with analytical-grade chemical salts utilizing $\mathrm{Pb}\left(\mathrm{NO}_{3}\right)_{2}$, $\mathrm{As}_{2} \mathrm{O}_{3}, \mathrm{CuCl}_{2} \bullet \mathrm{H}_{2} \mathrm{O}$ and $\mathrm{K}_{2} \mathrm{Cr}_{2} \mathrm{O}_{7}$, respectively. The subsequent amount of metal solutions was prepared with proper dilution in deionized distilled water.

\section{Heavy-metal precipitation from multi-component system by the biosorbents}

A Plackett-Burman design (PBD) was used for examining the HM removal in a multi-component system by the two biosorbents. The PBD comprises 12 experimental runs using different combination levels of $\mathrm{Cu}(\mathrm{II}), \mathrm{Cr}(\mathrm{VI}), \mathrm{As}(\mathrm{III})$ and $\mathrm{Pb}$ (II) (Table 1). PBD experiments were imposed for examining the effect imparted by the operational parameters, multiple variables on a process and their synergistic effect more influentially (Nejad et al. 2010). The tool simultaneously facilitates in examining the factors influencing the response as well as for identifying their interactions (Sahoo et al. 2014). The lower and upper limits of the concentration for each of the heavy metals, i.e. $\mathrm{Cu}, \mathrm{Cr}$, $\mathrm{As}$ and $\mathrm{Pb}$ were selected as 10 and $25 \mathrm{mg} \mathrm{L}^{-1}$, respectively. All these initial levels of the HMs were according to single component studied earlier using the similar biosorbents (Bind et al. 2018). The results obtained were statistically analyzed by Minitab (Version 16, PA, USA).

Each batch of multi-component biosorption experiments was carried out in 250-mL Erlenmeyer flasks with $100 \mathrm{~mL}$ of the HM contaminated solution. The experimental flasks were then incubated at $30^{\circ} \mathrm{C}$ on a rotary shaker at $120 \mathrm{rpm}$. Control flasks were also kept for all the 12 experimental runs. The samples were periodically taken from each experimental run to determine the individual HM concentration in the multi-component system.

\section{Characterization of the metal-loaded biosorbent}

FTIR spectroscopy and FESEM-EDX were carried out to characterize the HM-loaded biomass obtained due to the two biosorbents. FTIR spectrum was performed to determine the variations in the biomass functional groups due to HM biosorption. For FTIR spectra, the control and metalloaded biomass were centrifuged for $5 \mathrm{~min}$ at $8000 \times \mathrm{g}$, 
Table 1 Plackett-Burman experimental design matrix showing different combination levels of the heavy metals in the study along with the removal of metals by Azolla filiculoides and Hydrilla verticillata

\begin{tabular}{|c|c|c|c|c|c|c|c|c|c|c|c|c|}
\hline \multirow[t]{3}{*}{ Exp. run } & \multirow[t]{3}{*}{$\mathrm{Cu}$} & \multirow[t]{3}{*}{$\mathrm{Pb}$} & \multirow[t]{3}{*}{ As } & \multirow[t]{3}{*}{$\mathrm{Cr}$} & \multicolumn{8}{|c|}{ Metal removal (\%) } \\
\hline & & & & & \multicolumn{4}{|c|}{ Azolla filiculoides } & \multicolumn{4}{|c|}{ Hydrilla verticillata } \\
\hline & & & & & $\mathrm{Cu}(\%)$ & $\mathrm{Pb}(\%)$ & As $(\%)$ & $\mathrm{Cr}(\%)$ & $\mathrm{Cu}(\%)$ & $\mathrm{Pb}(\%)$ & As (\%) & $\mathrm{Cr}(\%)$ \\
\hline 1 & 25 & 25 & 10 & 25 & 60.0 & 57.2 & 52.7 & 38.8 & 51.7 & 76.3 & 48.8 & 48.9 \\
\hline 2 & 10 & 10 & 25 & 25 & 61.1 & 68.9 & 54.9 & 45.6 & 61.4 & 76.9 & 57.6 & 52.1 \\
\hline 3 & 10 & 10 & 10 & 10 & 68.3 & 81.4 & 62.7 & 51.2 & 71.2 & 84.3 & 65.3 & 55.2 \\
\hline 4 & 25 & 10 & 25 & 10 & 63.1 & 71.2 & 56.2 & 43.1 & 59.4 & 74.1 & 55.9 & 51.7 \\
\hline 5 & 10 & 25 & 10 & 10 & 67.1 & 76.1 & 59.8 & 47.8 & 63.2 & 78.4 & 59.7 & 53.8 \\
\hline 6 & 25 & 10 & 25 & 25 & 57.1 & 62.1 & 48.6 & 46.7 & 55.2 & 70.4 & 52.1 & 50.3 \\
\hline 7 & 25 & 25 & 25 & 10 & 58.3 & 64.3 & 50.1 & 42.1 & 49.4 & 74.1 & 46.5 & 48.1 \\
\hline 8 & 10 & 10 & 10 & 25 & 69.8 & 78.3 & 61.2 & 49.2 & 67.2 & 82.3 & 63.8 & 54.7 \\
\hline 9 & 10 & 25 & 25 & 25 & 56.2 & 60.1 & 43.1 & 39.1 & 53.5 & 78.3 & 50.4 & 49.4 \\
\hline 10 & 10 & 25 & 25 & 10 & 54.1 & 66.1 & 52.3 & 41.9 & 57.1 & 72.7 & 53.9 & 51.0 \\
\hline 11 & 25 & 25 & 25 & 25 & 46.5 & 64.2 & 44.2 & 36.7 & 48.9 & 67.2 & 46.1 & 38.1 \\
\hline 12 & 25 & 10 & 10 & 10 & 65.2 & 73.9 & 57.1 & 49.2 & 65.9 & 80.1 & 61.7 & 54.2 \\
\hline
\end{tabular}

washed twice with distilled water and the resulting pellet was vacuum-dried and subjected to FTIR spectroscopy (PerkinElmer, Singapore) (Goswami et al. 2017b). For FESEM analysis, the same metal-loaded biomass obtained after the experimental runs were dried in oven at $80^{\circ} \mathrm{C}$ for $2 \mathrm{~h}$ and coated with gold using a sputter coater (Goswami et al. 2017c). The prepared samples were then analyzed by FESEM-EDX (Zeiss, Sigma, Germany) for surface morphology and elemental composition.

\section{Analytical methods}

After the completion of the experiments, the samples were centrifuged at $4000 \times \mathrm{g}$ for $5 \mathrm{~min}$. The supernatant obtained was examined by atomic absorption spectroscopy (PerkinElmer Analyst 400, England) as per the American Public Health Association standards (APHA 2005):

Heavy metal removal $(\%)=\frac{\left(C_{0}-C_{e}\right)}{C_{0}} \times 100$

where $C_{0}$ and $C_{e}$, the initial and final HM concentrations $\left(\mathrm{mg} \mathrm{L}^{-1}\right)$ present in the solutions, respectively.

\section{Results}

\section{Heavy-metal removal from multi-component system}

The removal efficiencies of $\mathrm{Cu}(\mathrm{II}), \mathrm{Pb}(\mathrm{II}), \mathrm{As}(\mathrm{III})$ and $\mathrm{Cr}(\mathrm{VI})$ by the two different types of macrophytes, i.e., Azolla filiculoides (floating) and Hydrilla verticillata (submerged) in a multi-component polluted system, were examined in this study. HM removal was assorted in accordance with the combination level of these HMs in the respective mixture system. The maximum $\mathrm{Pb}$ (II) removal was obtained for both the biosorbents, i.e., Azolla sp. (81.4\%) and Hydrilla sp. $(84.3 \%)$ within $4 \mathrm{~h}$ of the experimental runs, with an initial concentration of $10 \mathrm{mg} \mathrm{L}^{-1}$ of all the HMs. Followed by $\mathrm{Pb}(\mathrm{II})$ removal, a declining trend in the removal (\%) for $\mathrm{Cu}(\mathrm{II}), \mathrm{As}(\mathrm{III})$ and $\mathrm{Cr}(\mathrm{VI})$, for all the experimental runs, was obtained, with a maximum of $68.3,62.7$ and $51.2 \%$ for Azolla sp. and 71.2, 65.3 and 55.2\% for Hydrilla sp., respectively. Also, the minimum removal (\%) for all the experimental runs was attained at $25 \mathrm{mg} \mathrm{L}^{-1}$ (maximum) for all the HM concentration levels. The removal efficiency trends follow the order: $\mathrm{Pb}$ (II) $>\mathrm{Cu}$ (II) $>\mathrm{As}$ (III) $>\mathrm{Cr}$ (VI) for both the biosorbents. Similar trend was also obtained in our earlier study (individual metal system), where the removal efficiencies were much higher in comparison with the present multi-component system (Bind et al. 2018). The removal efficiencies of HMs clearly depicted the dependency of HM removal by both the biosorbents onto the HMs type and their concentration combinations in the system. Here, the removal (\%) of different HMs for different experimental runs was related to their total removal.

\section{Statistical analysis}

For a superior perceptive and assessment of the relative significance of heavy metals on individual and each other in the multi-component simulated system, the results of metal removal obtained from the aqueous solution were statistically analyzed by Student's t test and variance analysis (ANOVA). The significance of HM removal multi-component system was evaluated by ANOVA, and the results are presented in Table 2 with $\mathrm{F}$ and $P$ values. The deviation in 
Table 2 Analysis of variance of heavy-metal removal from a multi-component system by Azolla filiculoides and Hydrilla verticillate

\begin{tabular}{|c|c|c|c|c|c|c|c|c|c|}
\hline \multirow[t]{2}{*}{ Source } & \multirow[t]{2}{*}{ DF } & \multicolumn{4}{|c|}{ Azolla filiculoides } & \multicolumn{4}{|c|}{ Hydrilla verticillate } \\
\hline & & SS & Adj MS & $F$ value & $P$ value & SS & Adj MS & $F$ value & $P$ value \\
\hline \multicolumn{10}{|l|}{$\mathrm{Cu}(\mathrm{II})$} \\
\hline Main effect & 4 & 386.01 & 96.50 & 4.20 & 0.048 & 503.46 & 125.865 & 66.02 & 0.000 \\
\hline $\mathrm{Cu}$ & 1 & 72.03 & 72.03 & 3.14 & 0.120 & 98.28 & 98.284 & 51.55 & 0.000 \\
\hline $\mathrm{Pb}$ & 1 & 171.76 & 171.76 & 7.48 & 0.029 & 188.32 & 188.321 & 98.78 & 0.000 \\
\hline As & 1 & 75.00 & 75.00 & 3.27 & 0.114 & 75.61 & 75.615 & 39.66 & 0.000 \\
\hline $\mathrm{Cr}$ & 1 & 67.21 & 67.21 & 2.93 & 0.131 & 32.57 & 32.566 & 17.08 & 0.004 \\
\hline Residual error & 7 & 160.70 & 22.97 & & & 13.35 & 1.906 & & \\
\hline Total & 11 & 546.80 & & & & 516.81 & & & \\
\hline \multicolumn{10}{|l|}{$\mathrm{Pb}(\mathrm{II})$} \\
\hline Main effect & 4 & 582.02 & 145.505 & 18.31 & 0.001 & 211.46 & 52.865 & 6.90 & 0.014 \\
\hline $\mathrm{Cu}$ & 1 & 120.33 & 120.333 & 15.14 & 0.006 & 51.52 & 51.520 & 6.73 & 0.036 \\
\hline $\mathrm{Pb}$ & 1 & 190.40 & 190.403 & 23.96 & 0.002 & 19.79 & 19.792 & 2.58 & 0.152 \\
\hline As & 1 & 122.88 & 122.880 & 15.46 & 0.006 & 82.14 & 82.140 & 10.73 & 0.014 \\
\hline $\mathrm{Cr}$ & 1 & 148.40 & 148.403 & 18.67 & 0.003 & 3.792 & 3.792 & 0.50 & 0.504 \\
\hline Residual error & 7 & 55.63 & 7.947 & & & 53.61 & 7.658 & & \\
\hline Total & 11 & 637.65 & & & & 265.07 & & & \\
\hline \multicolumn{10}{|l|}{ As(III) } \\
\hline Main effect & 4 & 357.56 & 89.391 & 7.77 & 0.010 & 469.59 & 117.39 & 92.00 & 0.000 \\
\hline $\mathrm{Cu}$ & 1 & 52.50 & 52.501 & 4.57 & 0.070 & 95.38 & 95.38 & 74.75 & 0.000 \\
\hline $\mathrm{Pb}$ & 1 & 123.52 & 123.521 & 10.74 & 0.014 & 169.18 & 169.18 & 132.59 & 0.000 \\
\hline As & 1 & 88.02 & 88.021 & 7.65 & 0.028 & 73.33 & 73.325 & 57.47 & 0.000 \\
\hline $\mathrm{Cr}$ & 1 & 93.52 & 93.521 & 8.13 & 0.025 & 29.04 & 29.04 & 22.76 & 0.002 \\
\hline Residual error & 7 & 80.50 & 11.500 & & & 8.932 & 1.276 & & \\
\hline Total & 11 & 438.06 & & & & 478.49 & & & \\
\hline \multicolumn{10}{|l|}{$\mathrm{Cr}(\mathrm{VI})$} \\
\hline Main effect & 4 & 190.27 & 47.568 & 7.85 & 0.010 & 177.29 & 44.32 & 5.70 & 0.023 \\
\hline $\mathrm{Cu}$ & 1 & 31.041 & 31.041 & 5.12 & 0.058 & 39.45 & 39.45 & 5.07 & 0.059 \\
\hline $\mathrm{Pb}$ & 1 & 117.19 & 117.187 & 19.33 & 0.003 & 55.02 & 55.02 & 7.08 & 0.032 \\
\hline As & 1 & 14.741 & 14.741 & 2.43 & 0.163 & 21.00 & 21.00 & 2.70 & 0.144 \\
\hline $\mathrm{Cr}$ & 1 & 27.301 & 27.301 & 4.5 & 0.072 & 25.30 & 25.3 & 3.25 & 0.114 \\
\hline Residual error & 7 & 42.44 & 6.063 & & & 54.41 & 7.77 & & \\
\hline Total & 11 & 232.71 & & & & 231.70 & & & \\
\hline
\end{tabular}

the results can be well described by the large $F$ value and corresponding low $P$ value which indicates the accuracy of the system. The values of the statistical parameters, viz., Fisher's $\mathrm{F}$ value, $P$-value and $\mathrm{R}^{2}$, together depict whether the level means are significant or not, along with the goodness of fit of the regression model. Thus, low $S$ value and high $R^{2}$ value show a precision of the model in estimating the experimental data.

Additionally, it was observed that the effect of individual metals on the removal of other metals in the multicomponent system was statistically significant (Table 2). To understand further, the individual effect by each of the HMs plays a significant role in their own removal in the multi-component system, Student's $t$ test was performed (Table 3). Student's $t$ test depicts the regression coefficient of the parameter and associates $P$ and $t$ values to specify their significance. Therefore, $\mathrm{Pb}$ (II) shows significant inhibitory effect on its removal (\%) and removal of other HMs with a $P$ value less than 0.01 for Azolla, but only shows the inhibitory effect on As and $\mathrm{Cu}$ for Hydrilla sp. (Table 3).While $\mathrm{Cu}$ (II) shows one-way inhibitory effect only in the case of Azolla sp. and for Hydrilla sp., it shows the inhibitory effect on all the metals present in the multi-component system (Fig. 1). In the case of As(III), it shows the inhibition for the individual as well as for $\mathrm{Pb}(\mathrm{II})$ and $\mathrm{Cr}(\mathrm{VI})$ for Azolla sp., while for Hydrilla sp. it shows the inhibition on all the respective selected heavy metals. Lastly, for $\mathrm{Cr}(\mathrm{VI})$, it shows negative effect on the removal of $\mathrm{Pb}(\mathrm{II})$ for both the biosorbents.

For a better presentation of the effect of various HMs on each other's removal in a multi-component simulated system, the Pareto chart is illustrated in Fig. 1. The horizontal bars in the Pareto chart shows the effect imposed by the 
Table 3 Significance of different heavy metals on each other's metal removal in the study in terms of Student's t-test

\begin{tabular}{|c|c|c|c|c|c|c|c|c|}
\hline \multirow[b]{2}{*}{ Term } & \multicolumn{4}{|c|}{ Azolla filiculoides } & \multicolumn{4}{|c|}{ Hydrilla verticillate } \\
\hline & Effect & Coeff & $T$ & $P$ & Effect & Coeff & $T$ & $P$ \\
\hline \multicolumn{9}{|c|}{ For $\mathrm{Cu}(\mathrm{II})$} \\
\hline $\mathrm{Cu}$ & -4.90 & -2.45 & -1.77 & 0.120 & -5.813 & -2.906 & -7.18 & 0.000 \\
\hline $\mathrm{Pb}$ & -7.57 & -3.78 & -2.73 & 0.029 & -8.046 & -4.023 & -9.94 & 0.000 \\
\hline As & -5.00 & -2.50 & -1.81 & 0.114 & -5.325 & -2.663 & -6.30 & 0.000 \\
\hline $\mathrm{Cr}$ & -4.73 & -2.37 & -1.71 & 0.131 & -3.346 & -1.673 & -4.13 & 0.004 \\
\hline \multicolumn{9}{|c|}{ For $\mathrm{Pb}(\mathrm{II})$} \\
\hline $\mathrm{Cu}$ & -6.333 & -3.167 & -3.89 & 0.006 & -4.208 & -2.104 & -2.59 & 0.036 \\
\hline $\mathrm{Pb}$ & -7.967 & -3983 & -4.89 & 0.002 & -2.608 & -1.304 & -1.61 & 0.152 \\
\hline As & -6.400 & -3.200 & -3.93 & 0.006 & -5.550 & -2.775 & -3.28 & 0.014 \\
\hline $\mathrm{Cr}$ & -7.033 & -3.517 & -4.32 & 0.000 & -1.142 & -0.571 & -0.70 & 0.504 \\
\hline \multicolumn{9}{|c|}{ For As (III) } \\
\hline $\mathrm{Cu}$ & -4.183 & -2.092 & -2.14 & 0.070 & -5.726 & -2.863 & -8.65 & 0.000 \\
\hline $\mathrm{Pb}$ & -6.417 & -3.208 & -3.28 & 0.014 & -7.626 & -3.813 & -11.51 & 0.000 \\
\hline As & -5.417 & -2.708 & -2.77 & 0.028 & -5.244 & -2.622 & -7.58 & 0.000 \\
\hline $\mathrm{Cr}$ & -5.583 & -2.792 & -2.85 & 0.025 & -3.159 & -1.580 & -4.77 & 0.002 \\
\hline \multicolumn{9}{|c|}{ For $\mathrm{Cr}(\mathrm{VI})$} \\
\hline $\mathrm{Cu}$ & -3.217 & -1.608 & -2.26 & 0.058 & -3.682 & -1.841 & -2.25 & 0.059 \\
\hline $\mathrm{Pb}$ & -6.250 & -3.125 & -4.40 & 0003 & -4.349 & -2.174 & -2.66 & 0.032 \\
\hline As & -2.217 & -1.108 & -1.56 & 0.163 & -2.806 & -1.403 & -1.64 & 0.144 \\
\hline $\mathrm{Cr}$ & -3.017 & 1.508 & -2.12 & 0.072 & -2.949 & -1.474 & -1.80 & 0.114 \\
\hline
\end{tabular}

Coeff Coefficient; $T T$ value; $P$ probability individual metals and the effects that is being extended to the head of the reference line (the vertical line on the chart) denoted the significant effects $(\leq 0.05)$. In general, the result shows that the increase in $\mathrm{Pb}$ (II) and $\mathrm{Cu}$ (II) concentrations in the multi-component system not only inhibits the individual removal (\%) by the two aquatic macrophytes, but also affects the removal of other HMs in the multi-component system, excluding $\mathrm{Cr}(\mathrm{VI})$ where the only significant effect was observed on $\mathrm{Pb}(\mathrm{II})$.

\section{Characterization of heavy-metal-loaded biomass}

For the characterization of the HM-loaded biomass, FESEM-EDX and FTIR analyses were performed to examine the surface morphology and elemental composition of the HM-loaded biomass. Figure 2a, b shows FESEM-EDX spectra of the metal-loaded biomass for both the biosorbents (Azolla and Hydrilla sp.). The presence of different selected HMs is confirmed by the EDX spectra obtained from the surface of the two biosorbents. In general, the result from FESEM shows that the selected HMs were mainly removed by biosorption associated with the surface of biosorbent.

FTIR analysis of the control and HM-loaded biomass for both the biosorbents was performed to examine the functional group(s) involved in the interactions between the heavy metal ions and on the surface of the biosorbents (Fig. 3). The stretch in both the spectra was in the range
$478-3650 \mathrm{~cm}^{-1}$ and $483-3661 \mathrm{~cm}^{-1}$ for the control and HMloaded biomass, respectively. The presence of $2921 \mathrm{~cm}^{-1}$ band corresponds to $-\mathrm{CH}_{2}$ (Das and Das 2015) followed by a peak at $1737 \mathrm{~cm}^{-1}$ (only in Hydrilla), which belongs to the carbonyl of ester groups. Bands enveloped from 1634 to $1648 \mathrm{~cm}^{-1}$ correspond to the primary amine, attributing to the amide I and II bands. A wide band spectrum at around $3250 \mathrm{~cm}^{-1}$ assigned O-H groups (Arul Manikandan et al. 2016).

\section{Discussion}

The mechanistic insights of the HM removal in a multicomponent system are very different from the single metalcontaminated system (Roy et al. 2015). The competiveness between different HMs and their inhibitory effect on each other plays a significant role in the biosorption phenomena in multi-component system which better/aptly resembles with the real wastewater-contaminated system (Gikas 2008), whereas the initial concentration also plays an important role in the heavy-metal removal in the single as well as in multicomponent systems (Babu et al. 2014; Baral et al. 2009). In the present study, the biosorption of the HMs involves the inhibitory effect on each other and it also increases with the increase in the HM concentration. Roy et al. (2015) also reported similar phenomena for the HM removal in 


\section{Azolla fliculoides}
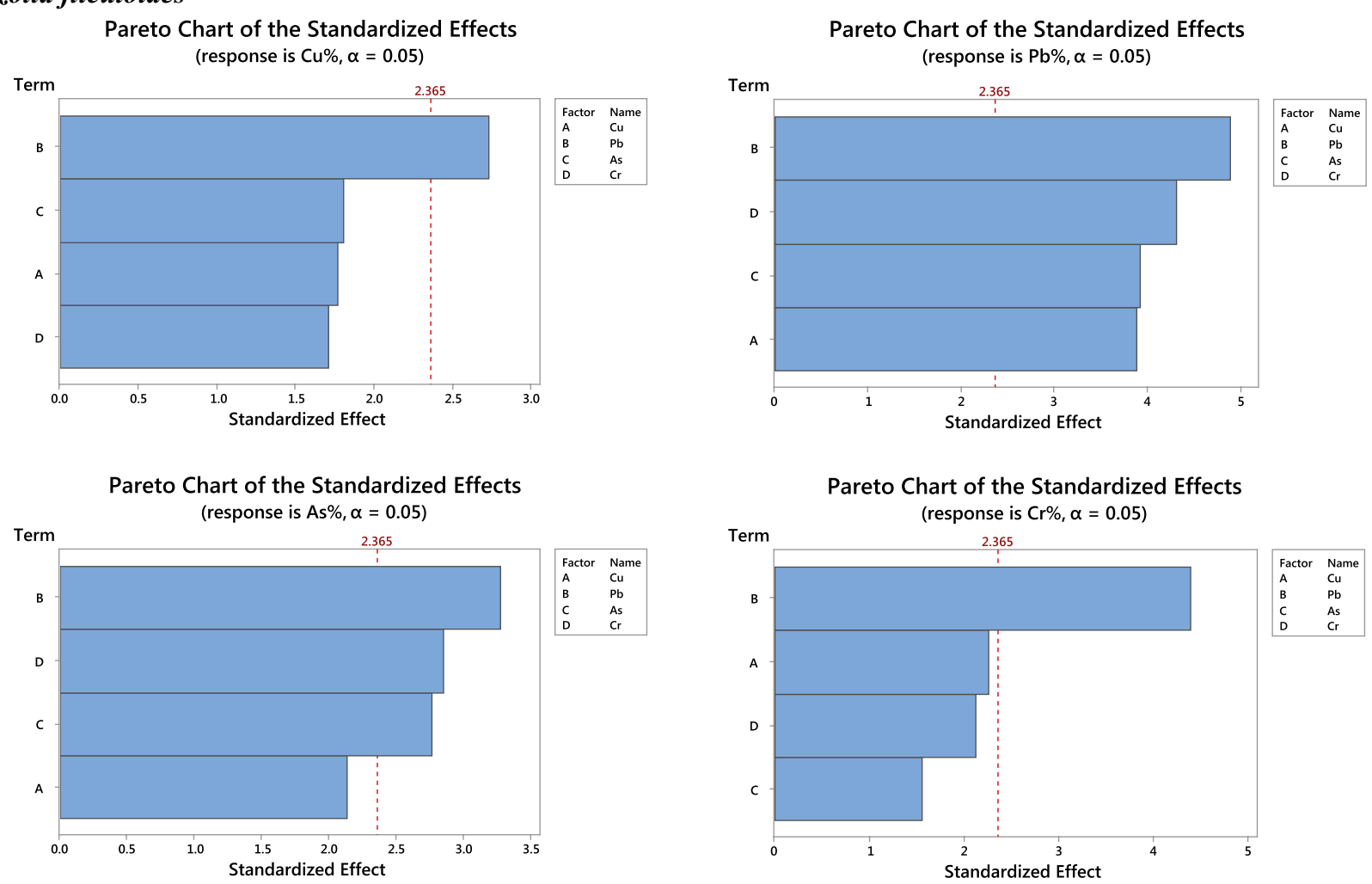

\section{Hydrilla verticillate}
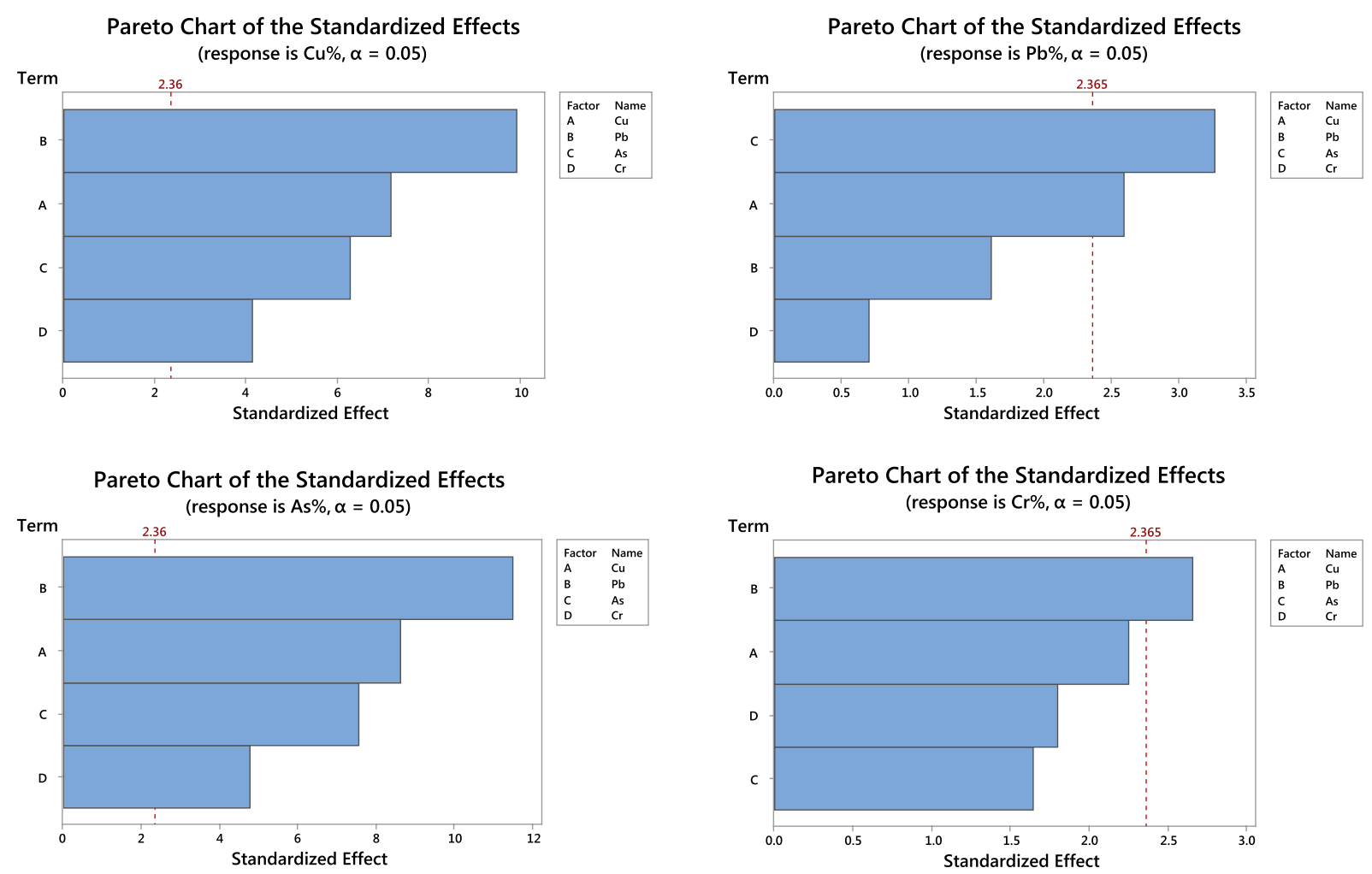

Fig. 1 Pareto chart showing the effect of different heavy metals on each other's removal by biosorbent: a Cu(II) removal, b Pb(II) removal, c As(III) removal and $\mathbf{d} \mathrm{Cr}(\mathrm{VI})$ removal (vertical line shows significant cutoff at $P$ value less than 0.05 ) 

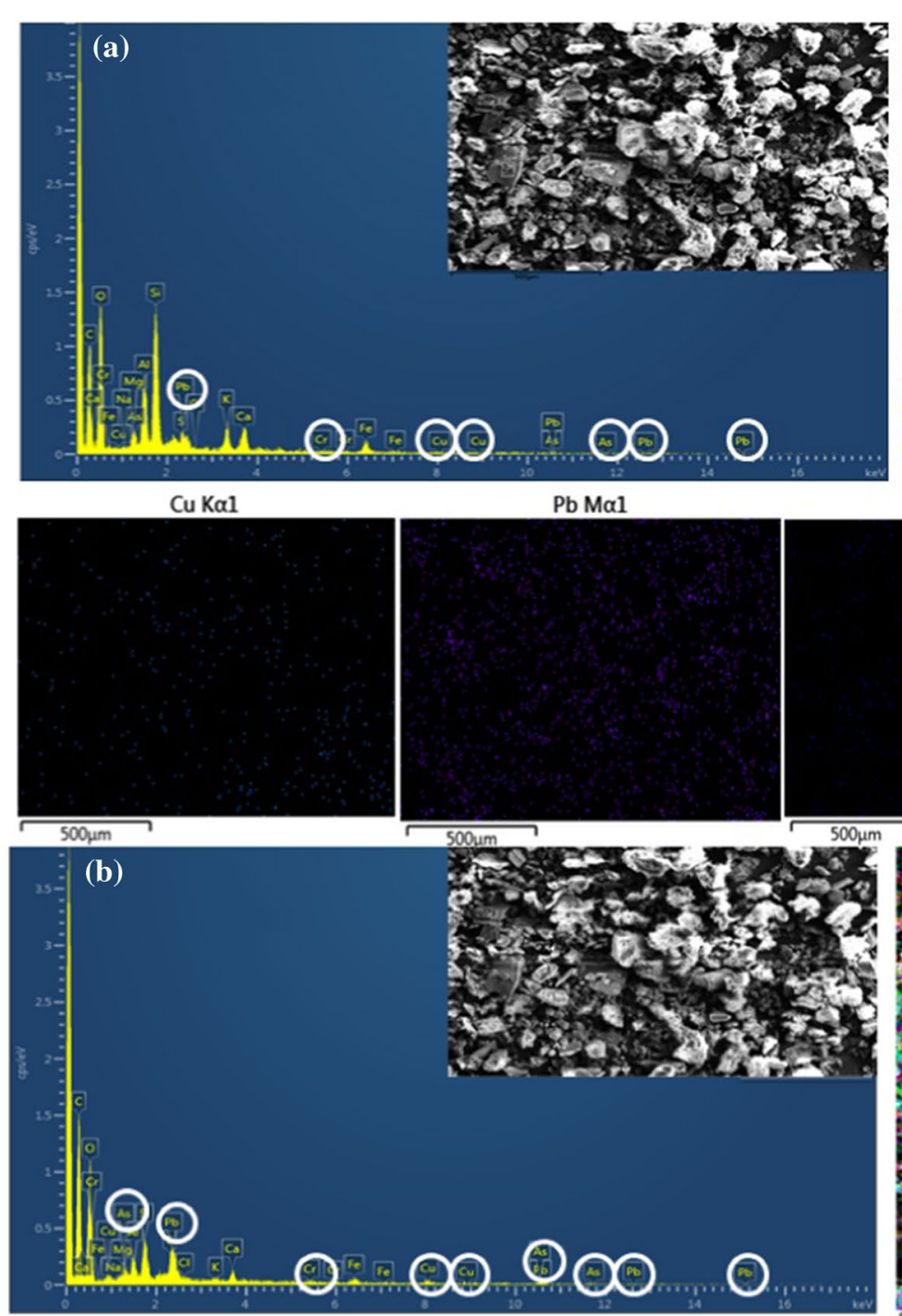

Cu Kal
$\mathrm{Pb} \mathrm{M} \alpha 1$

$\mathrm{Pb} \mathrm{M} \alpha 1$

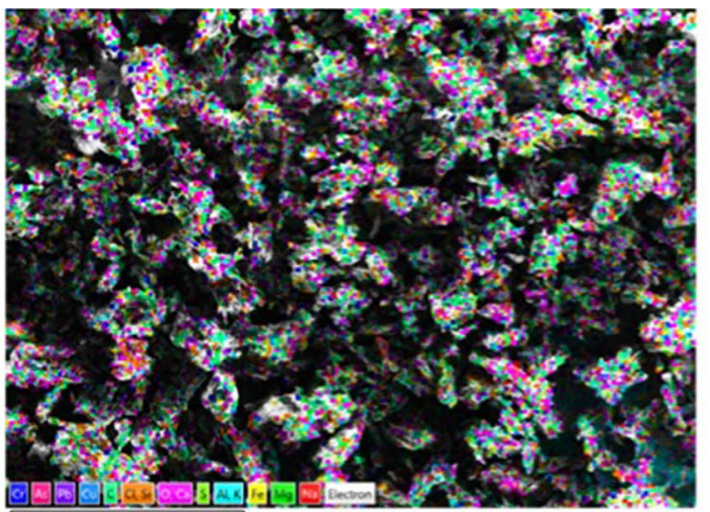

$\mathrm{Cr} \mathrm{Kal}{ }^{500}$

As $L a 1$ 2
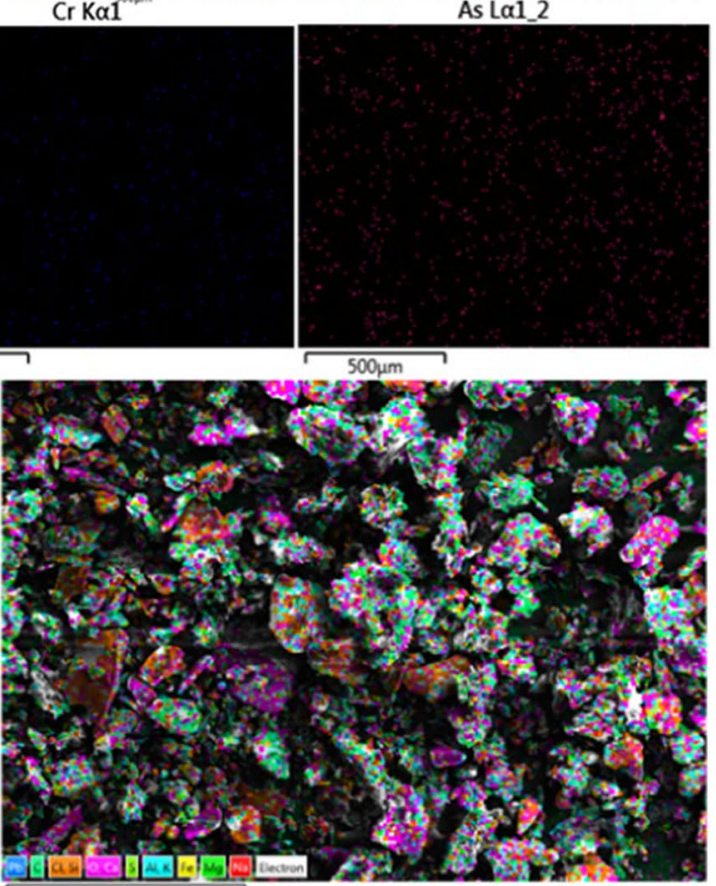

$\mathrm{Cr} K \alpha 1$

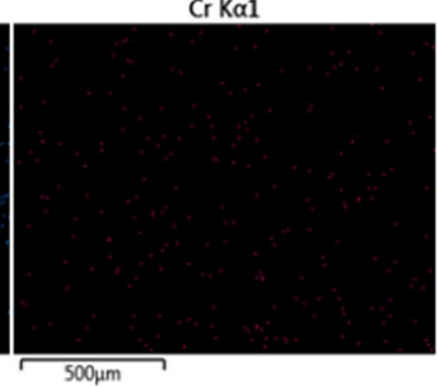

As La1_2

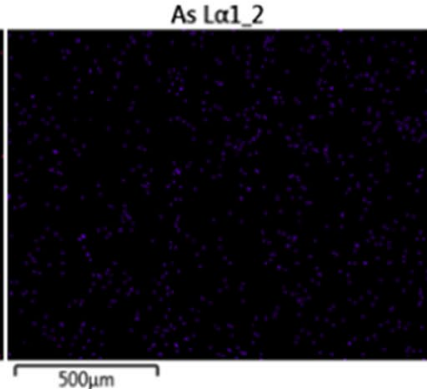

Fig. 2 FESEM micrographs and FESEM-EDX of a Azolla filiculoides and $\mathbf{b}$ Hydrilla verticillate, along with metal mapping

the multi-component system by Nostoc muscorum which involved very fast sorption initially onto the surface of cell, followed by lower uptake of the HMs inside the cyanobacteria. Also, $\mathrm{Pb}$ (II) showed a better removal in the multi-contaminated system containing three different heavy metals. Similar results were obtained in the current study as well as also in our earlier study in the single-component system (Bind et al. 2018).

In another study, Sulaymon et al. (2013) reported the competitive biosorption of $\mathrm{Pb}(\mathrm{II}), \mathrm{Cd}(\mathrm{II}), \mathrm{Cu}(\mathrm{II})$ and As(III) ions by using native algae in a multi-component system, viz., single, binary, ternary and quaternary metal solutions in a batch reactor. The removal of the heavy 

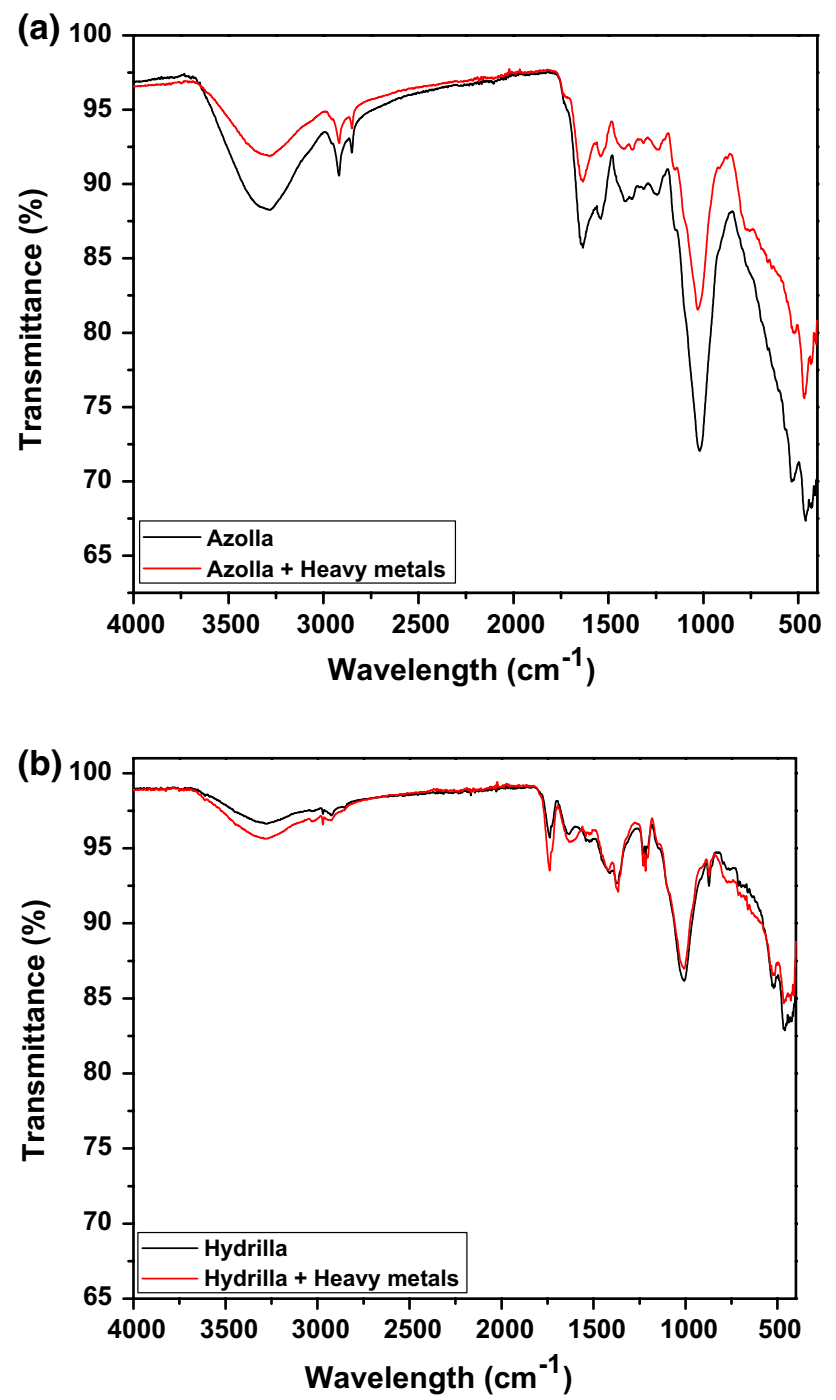

Fig. 3 FTIR spectra of the control biosorbent and metal-loaded biosorbent a Azolla filiculoides and $\mathbf{b}$ Hydrilla verticillata

metals followed $\mathrm{Pb}(\mathrm{II})>\mathrm{Cu}(\mathrm{II})>\mathrm{Cd}(\mathrm{II})>\mathrm{As}$ (III) trend with a declining affinity constant for the single, binary, ternary and quaternary, respectively. Also, the biosorption of all the metals tailed the pseudo-second-order kinetics model. $\mathrm{Pb}$ (II) biosorption could further be understood due to its strong affinity with the functional groups present in the biosorbent in comparison with the interactions because of the other HMs in multi-contaminated system. Also, the non-specific binding sites for $\mathrm{Pb}(\mathrm{II})$ present on the surface of macrophyte (biosorbent) attributed to its negative effect on each other's HM removal in the multicomponent system (Roy et al. 2015). The ionic radius of the metal hydrates also plays a significant role in the binding affinity. There is an inverse relation of the binding affinity with the radius of metal hydrates. Among all the selected $\mathrm{HMs}, \mathrm{Pb}$ (II) has the smallest radius (Chen et al. 2010). Moreover, the stereo-chemical hindrance and variation in the metal class behavior of $\mathrm{Pb}$ (II) resulted in an inhibitory effect on the removal of other HMs in the multi-component system (Tsezos and Remoundaki 1997).

Henceforth, it could be inferred that both the biosorbents are efficient in the removal of heavy metal, in particular $\mathrm{Pb}$ (II)- and $\mathrm{Cu}$ (II)-contaminated systems. Further, at higher concentration of the heavy-metals, surface modification can be performed chemically (with some acidic or basic reagents) that can be utilized for addition of function group onto the biosorbent (Ramrakhiani et al. 2017). In addition, the biosorbents have shown a good property of regeneration for its future as well.

\section{Conclusions}

Two different types of macrophytes were used as the potential biosorbents in a multi-component study; in both the cases, the following trend was obtained in accordance with their removal efficiencies: $\mathrm{Pb}$ (II) $>\mathrm{Cu}$ (II) $>\mathrm{As}$ (III) $>\mathrm{Cr}(\mathrm{VI})$. $\mathrm{As} \mathrm{Pb}(\mathrm{II})$ has a small hydrated ionic radius in comparison with the other chosen heavy metals, it has depicted a strong negative effect on the removal of other HMs by the macrophytes, except chromium. Hydrilla verticillata (submerged) have shown better removal efficiencies in comparison with Azolla filiculoides (floating) for all the experimental runs. Although the removal efficiencies in multi-component system, for both the cases, were less than the individual removal, the maximum removal was obtained at an initial concentration of $10 \mathrm{mg} \mathrm{L}^{-1}$. Also, the individual effect of each heavy metal significantly governs the removal efficiencies in all the cases. Hence, for all these heavy metals, both the macrophytes have shown very good potential for the removal in a multi-component-contaminated system.

Acknowledgements The authors thank Dr. Sumit Kumar Sonkar, Malaviya National Institute of Technology Jaipur, for his help in FESEM and FTIR analyses of the samples.

\section{Compliance with ethical standards}

Conflict of interest The authors declare that they have no conflict of interest.

Open Access This article is distributed under the terms of the Creative Commons Attribution 4.0 International License (http://creat ivecommons.org/licenses/by/4.0/), which permits unrestricted use, distribution, and reproduction in any medium, provided you give appropriate credit to the original author(s) and the source, provide a link to the Creative Commons license, and indicate if changes were made. 


\section{References}

Ahmad A, Bhat AH, Buang A (2018) Biosorption of transition metals by freely suspended and Ca-alginate immobilised with Chlorella vulgaris: kinetic and equilibrium modeling. J Clean Prod 171:1361-1375

Ahn KH, Hong SW (2015) Characteristics of the adsorbed heavy metals onto aerobic granules: isotherms and distributions. Desalin Water Treat 53(9):2388-2402

American Public Health Association (APHA) (2005) Standard methods for examination of water and wastewater. American Water Works Association, Water Environment Federation, Washington D.C.

Arul Manikandan N, Alemu AK, Goswami L, Pakshirajan K, Pugazhenthi G (2016) Waste litchi peels for Cr(VI) removal from synthetic wastewater in batch and continuous systems: sorbent characterization, regeneration and reuse study. J Environ Eng 142(9):C4016001

Babu DJ, Sumalatha B, Venkateswarulu TC, Das KM, Kodali VP (2014) Kinetic, equilibrium and thermodynamic studies of biosorption of Chromium(VI) from aqueous solutions using Azolla Filiculoidus. J Pure Appl Microbiol 8(4):3107-3116

Baral SS, Das N, Chaudhury GR, Das SN (2009) A preliminary study on the adsorptive removal of $\mathrm{Cr}(\mathrm{VI})$ using seaweed, Hydrilla verticillata. J Hazard Mater 171(1):358-369

Bind A, Goswami L, Prakash V (2018) Comparative analysis of floating and submerged macrophytes for heavy metal (copper, chromium, arsenic and lead) removal: sorbent preparation, characterization, regeneration and cost estimation. Geol Ecol Landsc 2(2):61-72

Chen SB, Ma YB, Chen L, Xian K (2010) Adsorption of aqueous $\mathrm{Cd}^{2+}$, $\mathrm{Pb}^{2+}, \mathrm{Cu}^{2+}$ ions by nanohydroxyapatite: single- and multi-metal competitive adsorption study. Geochem J 44:233-239

Das D, Das N (2015) Optimization of parameters for praseodymium (III) biosorption onto biowaste materials using response surface methodology: equilibrium, kinetic and regeneration studies. Ecol Eng 81:321-327

Gikas P (2008) Single and combined effects of nickel (Ni(II)) and cobalt (Co(II)) ions on activated sludge and on other aerobic microorganisms: a review. J Hazard Mater 159:187-203

Goswami L, Manikandan NA, Pakshirajan K, Pugazhenthi G (2017a) Simultaneous heavy metal removal and anthracene biodegradation by the oleaginous bacteria Rhodococcus opacus. 3 Biotech 7(1):37

Goswami L, Namboodiri MT, Kumar RV, Pakshirajan K, Pugazhenthi G (2017b) Biodiesel production potential of oleaginous Rhodococcus opacus grown on biomass gasification wastewater. Renew Energy 105:400-406

Goswami L, Kumar RV, Arul Manikandan N, Pakshirajan K, Pugazhenthi G (2017c) Anthracene biodegradation by Oleaginous Rhodococcus opacus for biodiesel production and its characterization. Polycyclic Aromat Compd 27:1-13

Goswami L, Kumar RV, Borah SN, Manikandan NA, Pakshirajan K, Pugazhenthi G (2018a) Membrane bioreactor and integrated membrane bioreactor systems for micropollutant removal from wastewater: a review. J water Process Eng 26:314-328

Goswami L, Manikandan NA, Dolman B, Pakshirajan K, Pugazhenthi $\mathrm{G}$ (2018b) Biological treatment of wastewater containing a mixture of polycyclic aromatic hydrocarbons using the oleaginous bacterium Rhodococcus opacus. J Clean Prod 196:1282-1291

Goswami L, Kumar RV, Pakshirajan K, Pugazhenthi G (2019) A novel integrated biodegradation-microfiltration system for sustainable wastewater treatment and energy recovery. J Hazard Mater 365:707-715

Ibrahim WM, Hassan AF, Azab YA (2016) Biosorption of toxic heavy metals from aqueous solution by Ulva lactuca activated carbon. Egypt J Basic Appl Sci 3(3):241-249

Kushwaha A, Rani R, Kumar S, Gautam A (2015) Heavy metal detoxification and tolerance mechanisms in plants: implications for phytoremediation. Environ Rev 23:1-13

Kushwaha A, Rani R, Kumar S (2017a) Mechanism of Soil-MetalMicrobe Interactions and their Implication on Microbial Bioremediation and Phytoremediation. In: Kumar P, Gurjar BR, Govil JN (eds) Environmental science and engineering. Biodegradation and bioremediation, vol 8, 1st edn. Studium Press LLC, New Delhi

Kushwaha A, Rani R, Kumar S, Thomas T, David AA, Ahmed M (2017b) A new insight to adsorption and accumulation of high lead concentration by exopolymer and whole cells of lead-resistant bacterium Acinetobacter junii $\mathrm{L}$. Pb1 isolated from coal mine dump. Environ Sci Pollut Res 24:10652-10661

Kushwaha A, Hans N, Rani R, Kumar S (2018) A critical review on speciation, mobilization and toxicity of lead in soil-microbe-plant system and bioremediation strategies. Ecotoxicol Environ Saf 147:1035-1045

Nejad SJ, Abolghasemi H, Moosavian MA, Golzary A, Maragheh MG (2010) Fractional factorial design for the optimization of hydrothermal synthesis of lanthanum oxide nanoparticles under supercritical water condition. J Supercrit Fluids 52(3):292-297

Ramrakhiani L, Halder A, Majumder A, Mandal AK, Majumdar S, Ghosh S (2017) Industrial waste derived biosorbent for toxic metal remediation: mechanism studies and spent biosorbent management. Chem Eng J 308:1048-1064

Roy AS, Hazarika J, Manikandan NA, Pakshirajan K, Syiem MB (2015) Heavy metal removal from multicomponent system by the cyanobacterium Nostoc muscorum: kinetics and interaction study. Appl Biochem Biotechnol 175(8):3863-3874

Sahoo NK, Pakshirajan K, Ghosh PK (2014) Evaluation of 4-bromophenol biodegradation in mixed pollutants system by Arthrobacter chlorophenolicus A6 in an upflow packed bed reactor. Biodegradation 25(5):705-718

Showqi I, Lone FA, Naikoo M (2018) Preliminary assessment of heavy metals in water, sediment and macrophyte (Lemna minor) collected from Anchar Lake, Kashmir, India. Appl Water Sci 8(3):80

Singh PK, Kushwaha A, Hans N, Gautam A, Rani R (2019) Evaluation of the cytotoxicity and interaction of lead with lead resistant bacterium Acinetobacter junii $\mathrm{Pb} 1$. Braz J Microbiol. https://doi. org/10.1007/s42770-019-00041-1

Sulaymon AH, Mohammed AA, Al-Musawi TJ (2013) Competitive biosorption of lead, cadmium, copper, and arsenic ions using algae. Environ Sci Pollut Res 20(5):3011-3023

Tsezos M, Remoundaki E (1997) Recent advances in the mechanistic understanding of metals mobility and interaction with microbial biomass. Res Microbiol 148:515-517

Volesky B (1990) Biosorption of heavy metals. CRC Press Inc., Boston, p 396

Publisher's Note Springer Nature remains neutral with regard to jurisdictional claims in published maps and institutional affiliations. 